\title{
Dados Preliminares dos Aspectos de Condicionamento Físico de Indivíduos com Transtorno Mental Grave do Estudo "Neurocognição - Relacionamento- Condicionamento (NRC)"
}

Cruz, Michele Santos da; Takeda, Osvaldo Hakio; Mattos, Karen M Gines; Alves, Ana Laura A.; Sant, Renato Del; Xavier Neto, Mauro; Scanavino, Marco de Tubino

Instituto de Psiquiatria, HCFMUSP — chele1213@gmail.com

Introdução: Os dados sobre intervenções específicas para as pessoas com transtorno mental grave (TMG) são muito limitados na América Latina. Normalmente pacientes com TMG apresentam consequências negativas sobre o condicionamento físico. o estudo "Neurocognição - Relacionamento- Condicionamento (NRC)" é um estudo de intervenção em hospital-dia para pacientes com TMG. Objetivo: Analisar a condição física dos pacientes com transtorno mental grave. Descrever o perfil dos pacientes em relação ao índice de massa corporal (IMC) e à relação cintura/quadril (RCQ). Métodos: Apresentamos os dados preliminares de avaliação de base dos primeiros 12 pacientes, que apresentavam uma transtorno mental crônico e comprometimento funcional extenso, mas não tinham um diagnóstico de transtorno mental orgânico. Todos passaram em entrevista psiquiátrica diagnóstica padronizada e avaliação antropométrica. Resultados: Dez $(83,3 \%)$ homens e duas $(16,7 \%)$ das mulheres foram incluídas no estudo. a idade média foi de 35,58 (DP = $12,00)$ e a média de anos de estudo foi de 14,33 (DP =4,38). Oito $(67 \%)$ indivíduos preencheram os critérios para esquizofrenia, quatro $(33,3 \%)$ para transtornos de humor. Seis $(50 \%)$ dos pacientes apresentaram sobrepeso e cinco $(41,7 \%)$ obesidade. Quatro $(33,3 \%)$ apresentaram baixo ou moderado e oito $(66,7 \%)$ apresentaram risco cardiovascular elevado ou superior com base na relação cintura-quadril. Conclusões: a amostra apresentou indícios de precário condicionamento físico. Os resultados confirmam a relevância do estudo NRC.

Cruz, Michele Santos da; Takeda, Osvaldo Hakio; Mattos, Karen M Gines; Alves, Ana Laura A.; Sant, Renato Del; Xavier Neto, Mauro; Scanavino, Marco de Tubino. Dados Preliminares dos Aspectos de Condicionamento Físico de Indivíduos com Transtorno Mental Grave do Estudo "Neurocognição Relacionamento- Condicionamento (Nrc)". In: Anais do Congresso Internacional de Humanidades \& Humanização em Saúde [= Blucher Medical Proceedings, num.2, vol.1]. São Paulo: Editora Blucher, 2014. ISSN 2357-7282

DOI 10.5151/medpro-cihhs- 10775 